Article

\title{
An SPR Sensor Chip Based on Peptide-Modified Single-Walled Carbon Nanotubes with Enhanced Sensitivity and Selectivity in the Detection of 2,4,6-Trinitrotoluene Explosives
}

\author{
Jin Wang ${ }^{1,2, *}$, Sanyang Du 2,3, Takeshi Onodera ${ }^{2,3}$, Rui Yatabe ${ }^{2,3}$, Masayoshi Tanaka ${ }^{2,4}$, \\ Mina Okochi ${ }^{2,4}$ and Kiyoshi Toko ${ }^{1,2,5}$ \\ 1 Research and Development Center for Five-Sense Devices, Kyushu University, 744 Motooka, Nishiku, \\ Fukuoka 819-0395, Japan; toko@ed.kyushu-u.ac.jp \\ 2 JST, ImPACT, Sanban-cho 5, Chiyoda-ku, Tokyo 102-0075, Japan; du.sanyang.748@s.kyushu-u.ac.jp (S.D.); \\ onodera@ed.kyushu-u.ac.jp (T.O.); yatabe.rui.678@m.kyushu-u.ac.jp (R.Y.); \\ m_tanaka@chemeng.titech.ac.jp (M.T.); okochi@chemeng.titech.ac.jp (M.O.) \\ 3 Graduate School of Information Science and Electrical Engineering, Kyushu University, 744 Motooka, \\ Nishiku, Fukuoka 819-0395, Japan \\ 4 Department of Chemical Science and Engineering, Tokyo Institute of Technology, 2-12-1, O-okayama, \\ Meguro-ku, Tokyo 152-8552, Japan \\ 5 Institute for Advanced Study, Kyushu University, 744 Motooka, Nishiku, Fukuoka 819-0395, Japan \\ * Correspondence: wang.jin.335@m.kyushu-u.ac.jp; Tel.: +81-92-802-3762
}

Received: 20 November 2018; Accepted: 15 December 2018; Published: 17 December 2018

\begin{abstract}
In this study, we developed a surface plasmon resonance (SPR) sensor chip based on 2,4,6-trinitrotoluene (TNT) recognition peptide-modified single-walled carbon nanotubes (SWCNTs). The carboxylic acid-functionalized SWCNTs were immobilized on a 3-aminopropyltriethoxysilane (APTES)-modified SPR Au chip surface. Through $\pi$-stacking between the aromatic amino acids and SWCNTs, the TNT recognition peptide TNTHCDR3 was immobilized onto the surface of the SWCNTs. The peptide-SWCNTs-modified sensor surface was confirmed and evaluated by atomic force microscope (AFM) observation. The peptide-SWCNTs hybrid SPR sensor chip exhibited enhanced sensitivity with a limit of detection (LOD) of $772 \mathrm{ppb}$ and highly selective detection compared with commercialized carboxymethylated dextran matrix sensor chips.
\end{abstract}

Keywords: SPR; TNTHCDR3; SWCNTs; $\pi$-stacking; TNT analogues

\section{Introduction}

Surface plasmon resonance (SPR) is a powerful technique for the study of large biomolecule interactions in real time with a simple and rapid analysis procedure. SPR-based biosensing is widely used in medical diagnostics, pharmaceutical research, and food research, measuring the adsorption and desorption coefficients of the biomolecules. The principle of SPR is based on the fact that the signal is proportional to the refractive index (RI) of the medium near gold metal films. Therefore, any change in the environment of the medium $300 \mathrm{~nm}$ out from the surface will significantly change the signal [1-3]. Great effects have been achieved in enhancing SPR signals using gold nanoparticles/rods, quantum dots, graphene oxide, or carbon nanotubes [1,4-9]. Self-assembled monolayers and dextran polymers are often used for immobilizing the ligand molecules on the gold surface. However, these extensive effects on the enhancement of the SPR signal were still mainly used for the direct detection of large molecules, such as proteins, DNA, and antibodies, and for the indirect 
detection (competitive detection) of small molecules [6]. The detection of low concentrations of small molecules via direct detection is still challenging because of their insufficient mass for measurable change to the RI.

The synthesis and screening of 2,4,6-trinitrotoluene (TNT)-binding peptides for the direct detection of TNT explosives using SPR sensors has been previously investigated [10-12]. However, obtaining high sensitivity and selectivity has been hampered by SPR sensors without signal amplification. Therefore, we aim to develop a peptide-functionalized single-walled carbon nanotubes (SWCNTs) hybrid-anchored SPR sensor chip for enhanced sensitivity and selectivity. SWCNTs consist of only one graphene layer rolled in on itself, forming a tube shape; exhibit unique electrical/optical properties, and excellent biocompatibility; and are recognized as an excellent candidate for SPR enhancement [13-16]. Moreover, SWCNTs can be easily functionalized for bioreceptors, such as DNA strands or peptides, through $\pi$-stacking $[17,18]$. SWCNTs with diameters of a few nanometers keep the interaction between the bioreceptor and the analytes in the effective range where the changes in the refractive index within the electric field could be measured sensitively. In this study, TNTHCDR3 (15-amino acid sequence: ARGYSSFIYWFFDFC), demonstrated to be a TNT recognition peptide [10-12], was enriched in three kinds of aromatic amino acids ( $\mathrm{Y}$, tyrosine; $\mathrm{W}$, tryptophan; and $\mathrm{F}$, phenylalanine), which bind to the SWCNTs surface through noncovalent bonding via $\pi-\pi$ interactions. The results reveal that the proposed method offers enhanced sensitivity, selectivity, and long-term stability in the detection of TNT explosives.

\section{Materials and Methods}

\subsection{Materials and Reagents}

TNT and RDX (Research Development eXplosive)solutions $(10.03 \mathrm{mg} / \mathrm{mL})$ dissolved in pure DMF (N,N-dimethylformamide) were obtained from Chugoku Kayaku, Co., Ltd., Kure, Japan and were freshly diluted with phosphate-buffered saline (PBS, $0.1 \mathrm{M}, \mathrm{pH} 7.4$ ) containing $0.05 \%$ Tween $20(\mathrm{~T}$ ) and $1 \% \mathrm{DMF}$, as required. 2,4-dinitrophenyl glycine, 2,6-dinitrotoluene, and 4-nitrobenzoyl-glycyl-glycine were purchased from Tokyo Chemical Industry, Tokyo, Japan. 3-aminopropyltriethoxysilane (APTES) was purchased from Sigma-Aldrich, St. Louis, MO, USA. The SPR sensor chip (bare gold) and sensor chip CM7 (carboxymethylated dextran, designed for the detection of small molecules) were purchased from GE Healthcare, Uppsala, Sweden. Sodium hydroxide solution $(\mathrm{NaOH})$ and potassium hydroxide solution $(\mathrm{KOH})$ were purchased from FUJIFILM Wako Pure Chemical Industries, Tokyo, Japan. $N, N^{\prime}$-dicyclohexylcarbodiimide (DCC) was purchased from Sigma-Aldrich, St. Louis, MO, USA. Single-walled carbon nanotubes with carboxylic acid functionalization (SWCNTs) were purchased from Sigma-Aldrich, St. Louis, MO, USA. Piranha solution consisting of sulfuric acid $\left(\mathrm{H}_{2} \mathrm{SO}_{4}\right)$ and hydrogen peroxide $\left(\mathrm{H}_{2} \mathrm{O}_{2}\right)$ solution was purchased from Sigma-Aldrich, St. Louis, MO, USA (piranha solution cleaning must be operated in a fume hood with adequate safety protection). Potassium ferricyanide $\left(\mathrm{K}_{3}\left[\mathrm{Fe}(\mathrm{CN})_{6}\right]\right)$ and potassium chloride $(\mathrm{KCl})$, used for the cyclic voltammetry $(\mathrm{CV})$ of the SWCNTs, were purchased from FUJIFILM Wako Pure Chemical Industries, Tokyo, Japan. All the other chemicals were purchased either from Tokyo Chemical Industry, Tokyo, Japan, or FUJIFILM Wako Pure Chemical Industries, Tokyo, Japan. All the aqueous solutions were prepared using Milli-Q deionized water $(18 \mathrm{M} \Omega$ ) from a Milli-Q system (Millipore Corporation, Billerica, MA, USA).

\subsection{Fabrication Procedure of the Peptide-Functionalized SPR Sensor Chip Surface}

The TNT-binding peptide was determined to be TNTHCDR3 (ARGYSSFIYWFFDFC) according to our previous work [10-12]. A SPR sensor chip covered with a 50-nm gold layer was used for multistep functionalization (Figure 1). The surface modification procedure was conducted as follows. First, the bare gold SPR sensor chip was cleaned with a mixed solution consisting of ammonia solution, hydrogen peroxide, and Milli-Q water with a volume ratio of 2:2:10 at $90{ }^{\circ} \mathrm{C}$ for $20 \mathrm{~min}$. Next, the piranha solution was used to remove most of the contaminates on the gold surface to 
render it super clean. The gold chip was immersed in a $1 \% \mathrm{w} / \mathrm{v} \mathrm{KOH}$ solution $(90 \mu \mathrm{L})$ for at least $5 \mathrm{~min}$ to generate the hydroxyl groups. A $2 \%(v / v)$ APTES solution $(100 \mu \mathrm{L})$ was added onto the surface for $1.5 \mathrm{~h}$ to generate the amine groups. For preparing the SWCNT supernatant, $0.2 \mathrm{mg}$ of carboxylic acid-functionalized SWCNTs were dispersed in $5 \mathrm{~mL} \mathrm{DMF}$ with $0.5 \mathrm{mg}$ of DCC to convert the carboxylic groups into active carbodiimide esters [19,20]. The 5-mL DMF solution with $0.2 \mathrm{mg}$ of carboxylic acid-functionalized SWCNTs was firstly sonicated for $20 \mathrm{~min}$ in an ultrasonic bath (chilled ice was added to control the bath temperature at $25^{\circ} \mathrm{C}$ ). Then, the suspension was carefully extracted for centrifugation for $40 \mathrm{~min}$ at 13,200 rpm. A stable SWCNT supernatant with no precipitate was obtained and was ready for use for the sensor chip surface fabrication. Then, the APTES-modified sensor surface was immersed into the SWCNTs with the active carbodiimide ester solution forming amide bonds for $3.5 \mathrm{~h}$. Subsequently, TNTHCDR3 peptide at a concentration of $600 \mathrm{ppm}$ (prepared in $90 \%$ DMF solvent) was non-covalently immobilized on the SWCNT surfaces through $\pi-\pi$ interaction. The evaluation of the peptide-SWCNT-based SPR sensor chip was performed using a Biacore X100 instrument. Then, 8 ascending TNT sample solutions (i.e., $0.8 \mathrm{ppm}, 1.6 \mathrm{ppm}, 3.2 \mathrm{ppm}, 6.3 \mathrm{ppm}$, $12.5 \mathrm{ppm}, 25 \mathrm{ppm}, 50 \mathrm{ppm}$, and $100 \mathrm{ppm}$ ) were prepared and injected in triplicate for $80 \mathrm{~s}$ at a flow rate of $10 \mu \mathrm{L} / \mathrm{min}$. Mild regeneration of the sensor surface was performed using $5 \mathrm{mM} \mathrm{NaOH}$ at the end of each measurement. A $1 \%$ DMF solution was added into the running buffer solution to eliminate the bulk effects caused by the DMF. Flow and injection of the running buffer solution were conducted for system priming before each sample measurement. DMSO solution ( $5 \%$ and $10 \%)$ was applied to super clean the system after the total measurements.

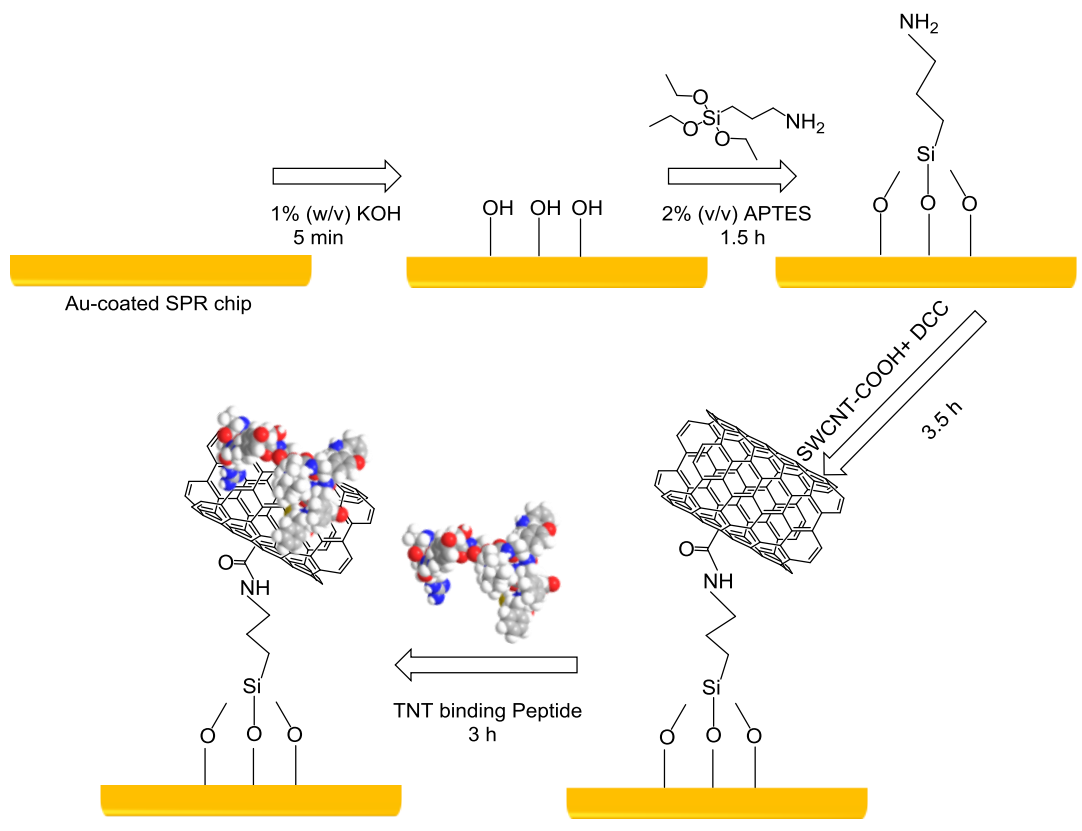

Figure 1. A schematic illustration of the immobilization procedure of the 2,4,6-trinitrotoluene (TNT)-binding peptide TNTHCDR3 on the surface of a single-walled carbon nanotube (SWCNT)-based surface plasmon resonance (SPR) gold-coated chip.

\section{Results and Discussion}

\subsection{TNT Recognition Peptide (TNTHCDR3) and SWCNT-Modified SPR Sensor Chip}

Three kinds of aromatic amino acids ( $\mathrm{Y}$, tyrosine; $\mathrm{W}$, tryptophan; and $\mathrm{F}$, phenylalanine) in the TNT recognition peptide sequence TNTHCDR3 (ARGYSSFIYWFFDFC) take an active part in binding to the TNT molecules via hydrogen bonding $(\mathrm{W})$ and $\pi$ electron-mediated effects $(\mathrm{Y}, \mathrm{W}$, and F) $[21,22]$. Using noncovalent bonding via $\pi-\pi$ interactions without damaging the intrinsic properties of the SWCNTs, the TNT recognition peptide was anchored onto the SWCNT-based SPR 
sensor chip surface. The surface structure and morphology of the peptide-SWCNT hybrid were analyzed by AFM. The morphology of the pristine SWCNTs $(40 \mu \mathrm{g} / \mathrm{mL}$ in DMF) on a mica substrate and on a SPR gold-coated chip was determined by AFM and is shown in Figure 2a,b. Well-dispersed SWCNTs could be observed on both surfaces. Noncovalent binding via $\pi-\pi$ interaction between TNTHCDR3 and SWCNTs is demonstrated in Figure 2c (on a mica substrate) and Figure 2d (on a SPR gold surface). In those figures, the bright dot, along with the SWCNTs, indicates the peptide unit. The AFM analysis results demonstrated the conformation of the hybrid material on the surface. The immobilization procedure of the SWCNTs on the APTES-based gold surface was described above. A homogeneous stable suspension formed by $\pi-\pi$ interactions between the aromatic amino acids in the TNTHCDR3 peptide and the SWCNTs can be observed in Figure 2e. Figure $2 \mathrm{f}$ simulates the interaction between the TNTHCDR3 peptide and the SWCNTs, in agreement with the mechanism reported in a previous study [23]. Meanwhile, the comparison of the FT-NIR absorbance spectra in Figure $2 \mathrm{~g}$ between the pristine SWCNTs and the TNTHCDR3 peptide-functionalized SWCNTs in DMF solvent clearly shows that good dispersion occurred without aggregation [24]. To prove that the SWCNTs were successfully immobilized on the APTES-based SPR gold surface shown in Figure 2b, CV was performed for comparison with and without a SWCNT-modified gold surface. The scan rate was set to $100 \mathrm{~m} \mathrm{Vs}^{-1} . \mathrm{K}_{3}\left[\mathrm{Fe}(\mathrm{CN})_{6}\right](1 \mathrm{mM})$, and $\mathrm{KCl}(50 \mathrm{mM})$ in 10-mM phosphate buffer (pH 7.4) was used as the electrolyte [19]. Clearly, the SWCNT-modified gold surface offered greater ferricyanide reduction peak currents compared with the surface without SWCNT modification. The CV results reflect the larger surface area of the SWCNT-modified gold surface and the enhancement of the electron transfer (Figure 2h).
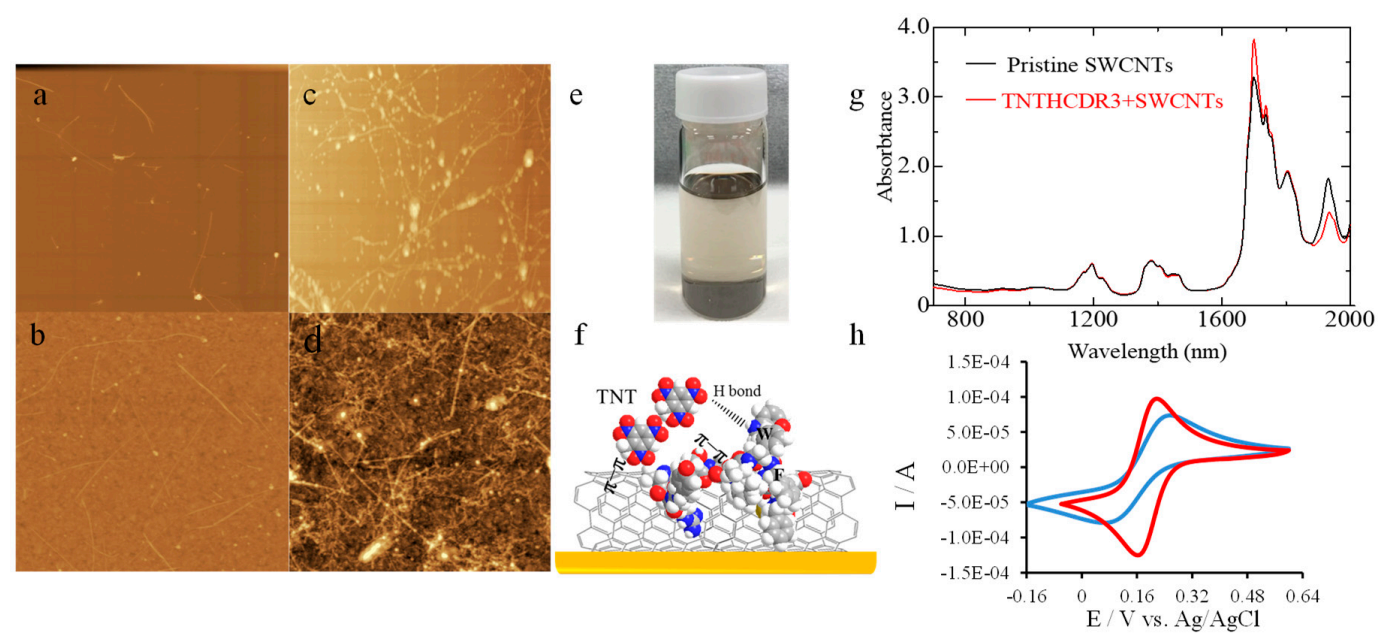

Figure 2. Atomic force microscope (AFM) analysis of the peptide-SWCNT-based SPR sensor surface fabrication procedure $(5 \mu \mathrm{m} \times 5 \mu \mathrm{m})(\mathrm{a} \sim \mathrm{d})$. (a) Pristine SWCNTs on a mica substrate; (b) SWCNTs on a 3-aminopropyltriethoxysilane (APTES)-based SPR Au-coated chip; (c) TNTHCDR3 anchored on SWCNTs on a mica substrate; (d) TNTHCDR3 anchored on a SWCNT-based gold surface; (e) Image of the mixed solution of TNTHCDR3 and SWCNTs; (f) Illustration of the $\pi-\pi$ interaction between TNTHCDR3 and SWCNTs, as well as the mechanism of 2,4,6-trinitrotoluene (TNT) binding to the peptide-SWCNT hybrids; (g) FT-NIR absorbance spectra of pristine SWCNTs and TNTHCDR3 peptide-functionalized SWCNTs; and (h) Cyclic voltammetry (CV) curves of bare gold (blue) and the SWCNT-modified gold chip (red).

\subsection{Performance of the Peptide-SWCNT-Based SPR Sensor}

Figure 3a shows the real-time sensorgrams of the peptide-SWCNT-based SPR to various TNT concentrations $(0 \mathrm{ppm} \sim 100 \mathrm{ppm})$. Compared with the results of using a conventional dextran chip (CM7 chip) in Figure 3b,c, the present peptide-SWCNT hybrid sensor chip exhibited a significantly higher response, revealing that SWCNTs are promising materials for low-molecular-weight (LMW) 
signal enhancement in lower concentrations [11,12]. Figure 3d shows the relationship between the SPR resonance unit (RU) and various concentrations of TNT explosives. The results in the Figure $3 \mathrm{~d}$ inset demonstrate a high linearity in the concentration range $0.8 \sim 12.5 \mathrm{ppm}\left(\mathrm{R}^{2}=0.9940\right)$. The limit

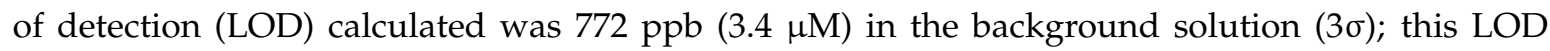
is competitive against using the peptide as a TNT receptor-based EIS (electrochemical impedance spectroscopy) $(1 \mu \mathrm{M})$, SERS (surface enhanced raman scattering) (100 pM), or QCM (quartz crystal microbalance) biosensor (not mentioned) [25-27]. However, the results revealed that the SPR sensor was still less sensitive when detecting small molecules with direct measurements, because they do not have sufficient mass to produce sufficiently high measurable signals at very low concentrations, as compared with using electric sensing methods, such as nanowire/SWCNTs-based FET (field effect transistor) with ppq level [28], $\mathrm{nM}$ level [29], or fM level [30] or three-dimensional (3D) microcantilevers with ppt level [31], using organic or bioreceptors for ultra-highly sensitive and selective TNT detection.
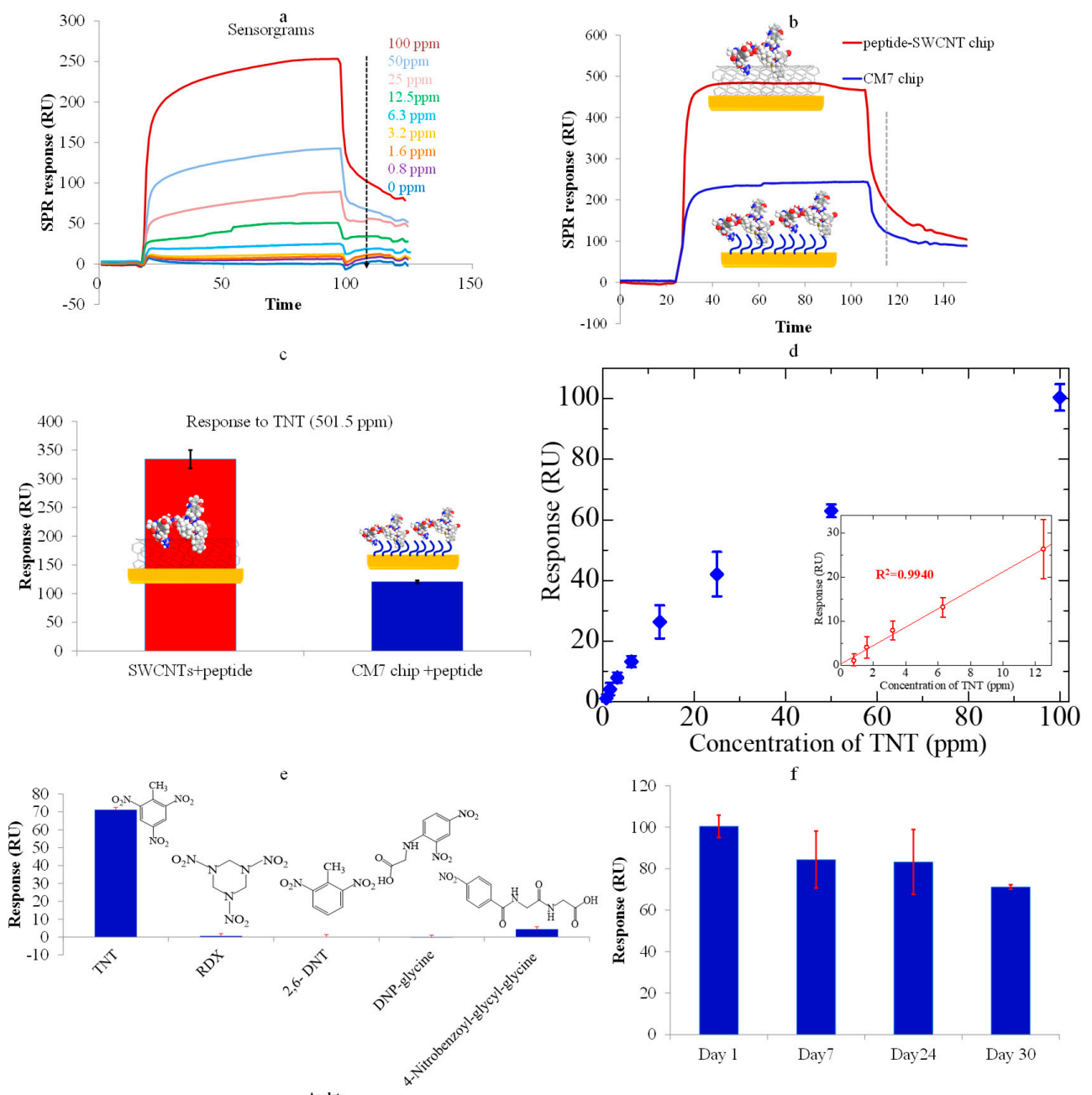

Figure 3. (a) The real-time sensorgrams of the peptide-SWCNT hybrids corresponding to TNT concentrations; (b) The real-time sensorgrams of two kinds of sensor chips corresponding to TNT explosives at a concentration of $501.5 \mathrm{ppm}$; (c) A comparison of the responses of two kinds of sensor chips to TNT solutions; (d) The responses of the SWCNT-peptide chip and CM7 chip to TNT (Inset: A plot of the response corresponding to various TNT concentrations in the highly linear range). The error bar indicates the calculated standard deviation $(n=3)$; (e) The response of the TNTHCDR3-anchored SWCNT sensor chip to 100 ppm solutions of TNT, RDX, 2,6-DNT, 4-nitrobenzoyl-glycyl-glycine, and DNP-glycine. The error bar indicates the calculated standard deviation $(n=3)$; (f) The stability of the sensor chip over a duration of 1 month (response to $100 \mathrm{ppm}$ TNT solution). 
Highly specific TNT detection and long-term stability were obtained by using the peptide-SWCNT-based SPR biosensor. The results in Figure 3e clearly show that the TNT explosive analogues, including DNP-glycine, 2,6-DNT, RDX, and 4-nitrobenzoyl-glycyl-glycine (at $100 \mathrm{ppm}$ concentration), had very small, negligible responses compared with the significant response to the TNT. The stability of the peptide-SWCNT hybrid-based SPR sensor was also evaluated over a period of 1 month. The concentration of the TNT sample was chosen to be $100 \mathrm{ppm}$, which required mild regeneration to the baseline ( 16 regeneration cycles using $5-\mathrm{mM} \mathrm{NaOH}$ solution for $10 \mathrm{~s}$ each time). The sensor response gradually decreased because of the reduced peptide activity mainly caused by the surface regeneration process or other effects during the storage period. As shown in Figure $2 \mathrm{f}$, the sensor response to $100 \mathrm{ppm}$ TNT explosives was about $84.0 \%$ of its original value after 1 week, $83.0 \%$ after 3 weeks, and $70.8 \%$ after 4 weeks. The results reveled an acceptable binding ability of the peptide-based SWCNT hybrid sensor chip.

\section{Conclusions}

To improve the performance of the SPR sensor for LMW detection, we presented a SPR sensor chip based on a peptide-modified SWCNT hybrid with long-term stability for enhanced sensitivity and high selectivity in the detection of TNT explosives. The sensor response was significantly amplified by the peptide-SWCNT hybrid, and nonspecific binding on the surface by other analogues was drastically reduced compared with that for the commercialized Biacore SPR CM7 sensor chip, as shown through direct determinations based on a previous investigation [11]. However, for ultra-highly sensitive detection of small molecule compounds, a peptide-SWCNT hybrid-based chemiresistor or FET platform is expected to be developed in future work based on the present progress.

Author Contributions: J.W. and T.O. conceived of and designed the experiments; J.W. and S.D. performed the experiments and analyzed the data; M.T. and M.O. contributed the peptide reagents, and R.Y. contributed materials/analysis tools; K.T., as the group leader, managed the project; J.W. wrote the paper; and all the authors revised the paper.

Funding: This research was funded by [Japan Science and Technology Agency] grant number [HQJJ268702].

Acknowledgments: This work was supported by the ImPACT Program ("Ultra-high-speed multiplexed sensing system beyond evolution for detection of extremely small amounts of substances"), the Council for Science, Technology, and Innovation (Cabinet Office, Government of Japan).

Conflicts of Interest: The authors declare no conflicts of interest.

\section{References}

1. Singh, M.; Holzinger, M.; Tabrizian, M.; Winters, S.; Berner, N.C.; Cosnier, S.; Duesberg, G.S. Noncovalently functionalized monolayer graphene for sensitivity enhancement of surface plasmon resonance immunosensors. J. Am. Chem. Soc. 2015, 137, 2800-2803. [CrossRef]

2. Arsenin, A.V.; Stebunov, Y.V. Biological Sensor and a Method of the Production of Biological Sensor. U.S. Patent 2015/0301039 A1, 22 October 2015.

3. Jang, D.; Na, W.; Kang, M.; Kim, N.; Shin, S. Ultrasensitive Detection of Single-Walled Carbon Nanotubes Using Surface Plasmon Resonance. Anal. Chem. 2016, 88, 968-973. [CrossRef] [PubMed]

4. Karajanagi, S.S.; Vertegel, A.A.; Kane, R.S.; Dordick, J.S. Structure and function of enzymes adsorbed onto single-walled carbon nanotubes. Langmuir 2004, 20, 11594-11599. [CrossRef]

5. Mech, L.D. Immunization with Peptide-Functionalized Carbon Nanotubes Enhances Virus-Specific Neutralizing Antibody Responses. Chem. Biol. 2003, 10, 961-966. [CrossRef]

6. Yuan, J.; Oliver, R.; Li, J.; Lee, J.; Aguilar, M.; Wu, Y. Sensitivity enhancement of SPR assay of progesterone based on mixed self-assembled monolayers using nanogold particles. Biosens. Bioelectron. 2007, 23, 144-148. [CrossRef] [PubMed]

7. Ghrera, A.S.; Pandey, M.K.; Malhotra, B.D. Quantum dot monolayer for surface plasmon resonance signal enhancement and DNA hybridization detection. Biosens. Bioelectron. 2016, 80, 477-482. [CrossRef] 
8. Wu, L.; Chu, H.S.; Koh, W.S.; Li, E.P. Highly sensitive graphene biosensors based on surface plasmon resonance. Opt. Express 2010, 18, 14395-14400. [CrossRef]

9. Stebunov, Y.V.; Aftenieva, O.A.; Arsenin, A.V.; Volkov, V.S. Highly Sensitive and Selective Sensor Chips with Graphene-Oxide Linking Layer. ACS Appl. Mater. Interfaces 2015, 7, 21727-21734. [CrossRef]

10. Okochi, M.; Muto, M.; Yanai, K.; Tanaka, M.; Onodera, T.; Wang, J.; Ueda, H.; Toko, K. Array-Based Rational Design of Short Peptide Probe-Derived from an Anti-TNT Monoclonal Antibody. ACS Comb. Sci. 2017, 19, 625-632. [CrossRef]

11. Wang, J.; Muto, M.; Yatabe, R.; Tahara, Y.; Onodera, T.; Tanaka, M.; Okochi, M.; Toko, K. Highly Selective Rational Design of Peptide-Based Surface Plasmon Resonance Sensor for Direct Determination of 2,4,6-trinitrotoluene (TNT) Explosive. Sens. Actuators B Chem. 2018, 264, 279-284. [CrossRef]

12. Wang, J.; Muto, M.; Yatabe, R.; Onodera, T.; Tanaka, M.; Okochi, M.; Toko, K. Rational design of peptide-functionalized surface plasmon resonance sensor for specific detection of TNT explosive. Sensors 2017, 17. [CrossRef] [PubMed]

13. Park, J.J.; Fagan, J.A.; Huh, J.Y.; Migler, K.B.; Karim, A.; Raghavan, D. SPR imaging study of DNA wrapped single wall carbon nanotube (ssDNA-SWCNT) adsorption on a model biological (collagen) substrate. Soft Matter 2010, 6, 5581-5588. [CrossRef]

14. Kakenov, N.; Balci, O.; Balci, S.; Kocabas, C. Probing molecular interactions on carbon nanotube surfaces using surface plasmon resonance sensors. Appl. Phys. Lett. 2012, 101, 223114. [CrossRef]

15. Sadrolhosseini, A.R.; Noor, A.S.M.; Bahrami, A.; Lim, H.N.; Talib, Z.A.; Mahdi, M.A. Application of polypyrrole multi-walled carbon nanotube composite layer for detection of mercury, lead and iron ions using surface plasmon resonance technique. PLoS ONE 2014, 9. [CrossRef] [PubMed]

16. Zhang, Y.; Arugula, M.A.; Kirsch, J.S.; Yang, X.; Olsen, E.; Simonian, A.L. Layer-by-layer assembled carbon nanotube-acetylcholinesterase/biopolymer renewable interfaces: SPR and electrochemical characterization. Langmuir 2015, 31, 1462-1468. [CrossRef]

17. Zorbas, V.; Smith, A.L.; Xie, H.; Ortiz-Acevedo, A.; Dalton, A.B.; Dieckmann, G.R.; Draper, R.K.; Baughman, R.H.; Musselman, I.H. Importance of aromatic content for peptide/single-walled carbon nanotube interactions. J. Am. Chem. Soc. 2005, 127, 12323-12328. [CrossRef]

18. Johnson, R.R.; Johnson, A.T.C.; Klein, M.L. Probing the structure of DNA-carbon nanotube hybrids with molecular dynamics. Nano Lett. 2008, 8, 69-75. [CrossRef]

19. Gooding, J.J.; Wibowo, R.; Liu, J.; Yang, W.; Losic, D.; Orbons, S.; Mearns, F.J.; Shapter, J.G.; Hibbert, D.B. Protein electrochemistry using aligned carbon nanotube arrays. J. Am. Chem. Soc. 2003, 125, 9006-9007. [CrossRef]

20. Drouvalakis, K.A.; Bangsaruntip, S.; Hueber, W.; Kozar, L.G.; Utz, P.J.; Dai, H. Peptide-coated nanotube-based biosensor for the detection of disease-specific autoantibodies in human serum. Biosens. Bioelectron. 2008, 23, 1413-1421. [CrossRef]

21. Jaworski, J.W.; Raorane, D.; Huh, J.H.; Majumdar, A.; Lee, S.W. Evolutionary screening of biomimetic coatings for selective detection of explosives. Langmuir 2008, 24, 4938-4943. [CrossRef]

22. Dower, S.K.; Gettins, P.; Jackson, R.; Dwek, R.A.; Givol, D. The binding of 2,4,6-trinitrophenyl derivatives to the mouse myeloma immunoglobulin A protein MOPC 315. Biochem. J. 1978, 169, 179-188. [CrossRef] [PubMed]

23. Pender, M.J.; Sowards, L.A.; Hartgerink, J.D.; Stone, M.O.; Naik, R.R. Peptide-mediated formation of single-wall carbon nanotube composites. Nano Lett. 2006, 6, 40-44. [CrossRef] [PubMed]

24. Backes, C.; Bosch, S.; Mundloch, U.; Hauke, F.; Hirsch, A. Density gradient ultracentrifugation on carbon nanotubes according to structural integrity as a foundation for an absolute purity evaluation. ChemPhysChem 2011, 12, 2576-2580. [CrossRef] [PubMed]

25. Zhang, D.; Jiang, J.; Chen, J.; Zhang, Q.; Lu, Y.; Yao, Y.; Li, S.; Logan Liu, G.; Liu, Q. Smartphone-based portable biosensing system using impedance measurement with printed electrodes for 2,4,6-trinitrotoluene (TNT) detection. Biosens. Bioelectron. 2015, 70, 81-88. [CrossRef] [PubMed]

26. Nergiz, S.Z.; Gandra, N.; Farrell, M.E.; Tian, L.; Pellegrino, P.M.; Singamaneni, S. Biomimetic SERS substrate: Peptide recognition elements for highly selective chemical detection in chemically complex media. J. Mater. Chem. A 2013, 1, 6543-6549. [CrossRef] 
27. Cerruti, M.; Jaworski, J.; Raorane, D.; Zueger, C.; Varadarajan, J.; Carraro, C.; Lee, S.W.; Maboudian, R.; Majumdar, A. Polymer-oligopeptide composite coating for selective detection of explosives in water. Anal. Chem. 2009, 81, 4192-4199. [CrossRef] [PubMed]

28. Lichtenstein, A.; Havivi, E.; Shacham, R.; Hahamy, E.; Leibovich, R.; Pevzner, A.; Krivitsky, V.; Davivi, G.; Presman, I.; Elnathan, R.; et al. Supersensitive fingerprinting of explosives by chemically modified nanosensors arrays. Nat. Commun. 2014, 5, 4195. [CrossRef] [PubMed]

29. Cao, A.; Zhu, W.; Shang, J.; Klootwijk, J.H.; Sudhölter, E.J.R.; Huskens, J.; de Smet, L.C.P.M. Metal-Organic Polyhedra-Coated Si Nanowires for the Sensitive Detection of Trace Explosives. Nano Lett. 2016. [CrossRef] [PubMed]

30. Kim, T.H.; Lee, B.Y.; Jaworski, J.; Yokoyama, K.; Chung, W.J.; Wang, E.; Hong, S.; Majumdar, A.; Lee, S.W. Selective and sensitive TNT sensors using biomimetic polydiacetylene-coated CNT-FETs. ACS Nano 2011, 5, 2824-2830. [CrossRef] [PubMed]

31. Spitzer, D.; Cottineau, T.; Piazzon, N.; Josset, S.; Schnell, F.; Pronkin, S.N.; Savinova, E.R.; Keller, V. Bio-inspired nanostructured sensor for the detection of ultralow concentrations of explosives. Angew. Chem. Int. Ed. 2012, 51, 5334-5338. [CrossRef]

(C) 2018 by the authors. Licensee MDPI, Basel, Switzerland. This article is an open access article distributed under the terms and conditions of the Creative Commons Attribution (CC BY) license (http://creativecommons.org/licenses/by/4.0/). 